\title{
CarbonMonoxide Poisoning with Classical Neurological Symptoms and CT Findings
}

\author{
Chiranjibi Pant ${ }^{1}$, Binod Karki', Biswo Shrestha ${ }^{2}$, Parag Karki ${ }^{1}$, Raju Paudel ${ }^{3}$ \\ ${ }^{1}$ Department of Medicine, Nepalese Army Institute of Health Sciences, ${ }^{2}$ Department of \\ Medicine, Vayodha Hospital, ${ }^{3}$ Department of Neurology, Grande Hospital.
}

\section{ABSTRACT}

Carbon monoxide (CO) is one of the leading causes of accidental poisonings. Mild poisoning produce symptoms like headaches, vertigo and flu like effects, whereas larger exposures can lead to significant toxicity of the central nervous system (CNS) including death. High index of suspicion is thus necessary specially while evaluating collection of such cases in winter months with a careful history taking. Here, we are reporting a case of suspected $\mathrm{CO}$ poisoning diagnosed on the basis of history, response to supportive treatment, exclusion of other causes, and classical computer tomographic findings.

Keywords: carbon monoxide; neurological, central nervous system

\section{INTRODUCTION}

Carbon monoxide (CO) is a byproduct of combustion by furnaces, heaters, and other fuel-powered devices used in homes. It is a colorless, odorless, highly toxic, nonirritating gas produced by incomplete combustion of hydrocarbons, is a relatively common cause of human injury. ${ }^{1} \mathrm{CO}$ poisoning is a preventable cause of morbidity and mortality. Human toxicity is often overlooked because $\mathrm{CO}$ is tasteless and odorless and its clinical symptoms and signs are nonspecific.

In Nepal, deaths following the exposure to smoke from burning charcoal or wood inside a closed room often make headlines in winter season, however there is not much scientific literature regarding such poisoning. We present a typical case of carbon monoxide poisoning who survived after aggressive supportive treatment whose diagnosis was possible after carefully analyzing the history and the presence of typical CT finding.

\section{CASE REPORT}

A 65-year-old male was brought to the emergency room in an unconscious state who was brought out of his room of his house; breaking the door three hours after he went inside and he didn't respond to the outside calls. According to the visitors there were remnants of burnt briquette coil inside a room. There was no evidence of seizures, vomiting, urinary and bowel incontinence or any kind of trauma at the time of incident and no history of fever, seizures, headache, and substance abuse in present or past. On evaluation, patient had GCS 10/15. Pupils were $2 \mathrm{~mm}$ bilaterally

Correspondence: Chiranjibi Pant, Department of Medicine, Shree Birendra Hospital, Chaunni, Kathmandu, Nepal. Email: drchiranjeevipant@gmail.com 
reacting to light with power in all four limbs $1 / 5$ and plantar reflex extensor on both the sides. There was no neck rigidity and fever at the time of presentation. Patient's blood pressure was $90 / 50 \mathrm{~mm} \mathrm{Hg}$, which responded later to fluid resuscitation. Systemic examination and investigations including cerebrospinal fluid (CSF) examination were normal. ABG during presentation showed marked hypoxemia with $\mathrm{paO}_{2}$ of $47 \mathrm{~mm} \mathrm{Hg}$. CT Head on the day of admission showed symmetrical low density round lesions in both basal ganglia regions (See figure 1, white arrows).

Analyzing the history and classical CT findings, diagnosis of carbon monoxide was made. Due to severe hypoxia and low level of consciousness he required mechanical ventilator support for initially three days with $100 \%$ oxygenation along with other supportive treatment. Patient was extubated on the fourth day with slight disorientation. He continued to receive supportive care till tenth day and at the time of discharge he was fully conscious and was able to walk with support and take care himself functionally.

\section{DISCUSSION}

Carbon monoxide $(\mathrm{CO})$ is a gas resulting from incomplete combustion. While almost certainly under-diagnosed, there are many documented serious poisonings every year most commonly from faulty gas heaters, burning briquettes, and house hold fire ${ }^{2}$. There is a spectrum of clinical features from headache, nausea, and flu-like symptoms through to coma with hyperventilation, convulsions, pulmonary edema, and myocardial ischemia including death.
The brain and the heart may be severely affected after CO exposure with carboxyhemoglobin $(\mathrm{COHb})$ levels exceeding $20 \%$. Damage occurs because the affinity of hemoglobin for $\mathrm{CO}$ is 210 times higher than for $\mathrm{O}_{2}$ and forms the $\mathrm{CO}-\mathrm{Hb}$ complex which impairs tissue oxygen delivery, inhibits mitochondrial oxidative phosphorylation, and inactivates cytochrome oxidase ${ }^{3}$. These lead to anoxic-ischemic encephalopathy, usually with bilateral lesions. It has been reported that the basal ganglia structures, globus pallidus, putamen, and caudate nucleus are most commonly affected by ischemic lesions. Also, thalamus, periventricular and subcortical white matter, corpus callosum, cerebral cortex, and hippocampus of the temporal lobe may be involved ${ }^{4}$.

The CT finding in our case was classical as mentioned in case series by Takashi $\mathrm{M}$ et $\mathrm{al}^{5}$ where out of 60 patients studied symmetric low densities round opacities in globus pallidus and white matters of cerebrum was the commonest findings. Jones $\mathrm{JS}$ et $\mathrm{al}^{6}$ also described the similar findings in the CT scans

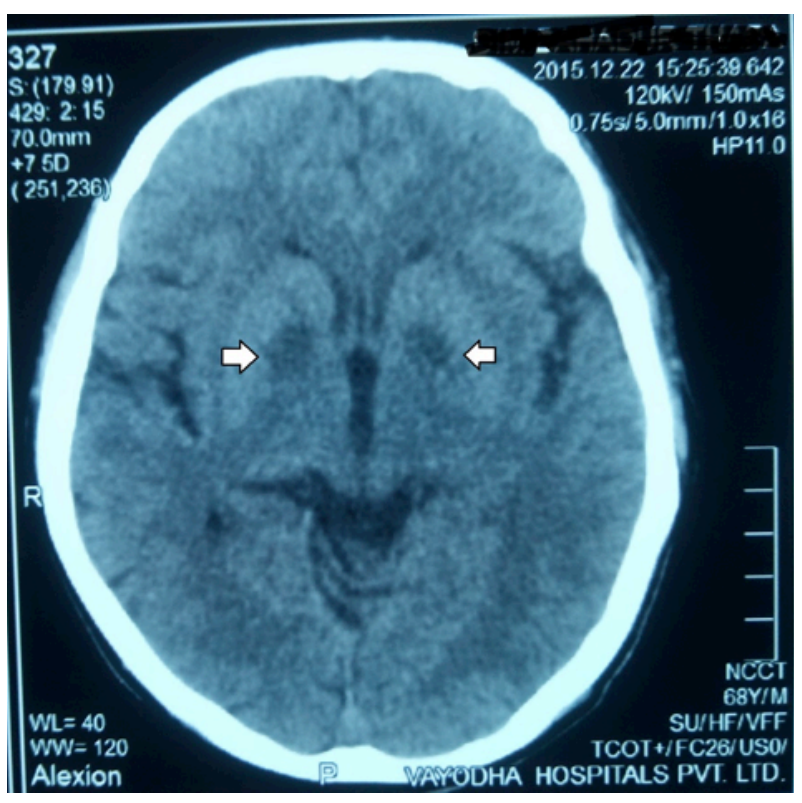

Figure I: CT scan of the patient. 
of the patients with $\mathrm{CO}$ poisoning and also mentioned that those with normal CT scan are more likely to get discharged with intact neurological functions.

The initial aims in the management are removal from the source, and administration of high-flow oxygen ${ }^{2}$. $\mathrm{CO}$ elimination has a dependent relationship with the $\mathrm{FiO}_{2}$. In room air the half-life of $\mathrm{COHb}$ is up to 5 hours; with high-flow oxygen and a reservoir mask this reduces to approximately 70 minutes; and hyperbaric oxygen reduces this further to about 25 minutes $^{3}$. Hyperbaric oxygen treatment is the gold standard when available however we could not offer it due to its nonavailability. We had given $100 \%$ oxygenation with mechanical ventilator support which is also described to be equally effective. It is seen that if diagnosed timely and treatment initiated, $\mathrm{CO}$ poisoning is a reversible hypoxic injury and patients show early recovery with adequate oxygenation and supportive measure.

\section{REFERENCES}

1. Abd El-Rahman El-Nagar, Radhwan NM. Carbon monoxide poisioning.Kasr El Aini Medical Journal.2010 Jun;16(2):41-50.

2. Hardy KR, Thom SR: Pathophysiology and treatment of carbon monoxide poisoning. J Toxicol Clin Toxicol. 1994, 32 (6): $613-29$. h t t p : / / d x.doi .org / 10.3109/15563659409017973

3. Weaver LK, Howe S, Hopkins R, Chan KJ: Carboxyhemoglobin half-life in carbon monoxide-poisoned patients treated with $100 \%$ oxygen at atmospheric pressure. Chest. 2000, 117 (3): 801-8. 10.1378/chest. 117.3.801. http://dx.doi.org/10.1378/chest. 117.3 .801
4. Silver DA, Cross M, Fox B, Paxton RM. Computed tomography of the brain in acute carbon monoxide poisoning. Clin Radiol. 1996 Jul;51(7):480-3. PubMed PMID: 8689822. http://dx.doi.org/10.1016/ s0009-9260(96)80186-3

5. Miura T, Mitomo M, Kawai R,Harada K. $\mathrm{CT}$ of the brain in acute carbon monoxide intoxication: characterstic features and prognosis.AJNR.1985;6:739-42.

6. Jones JS, Lagasse J,Zimmerman G.Computed tomographic findings after acute carbon monoxide poisoning. Am J Emerg Med.1994 Jul;12(4):448-51. http:// dx.doi.org/10.1016/0735-6757(94)90059-0. 